\title{
Gastrostomy as a Preemptive Measure after Pancreatoduodenectomy against Delayed Gastric Emptying: A Small Case Series and a Review of the Literature
}

\author{
G. Floros $\mathbb{D}$, I. Galanis $\mathbb{D}$, P. Theodoropoulos, D. Bartziotas, C. Theodoropoulos, M. Metaxa, \\ G. Giannos, P. Tsintavis, G. Stylianidis, and S. Klimopoulos
}

2nd Surgical Department Evaggelismos Hospital, Athens, Greece

Correspondence should be addressed to G. Floros; geoflo7@gmail.com

Received 29 November 2020; Revised 1 February 2021; Accepted 10 February 2021; Published 23 February 2021

Academic Editor: Dimitrios Mantas

Copyright ( 2021 G. Floros et al. This is an open access article distributed under the Creative Commons Attribution License, which permits unrestricted use, distribution, and reproduction in any medium, provided the original work is properly cited.

Delayed gastric emptying (DGE) is a common (20-30\%) postoperative complication following pancreatoduodenectomy (PD) (Parmar et al., 2013). Various causes and preemptive measures have been suggested to decrease the occurrence of DGE. We added a simple step in the procedure of 26 consecutive pancreatic head resections, which seems to alleviate DGE and has never been highlighted before.

\section{Background}

Delayed gastric emptying (DGE) is a common postoperative complication following pancreatoduodenectomy (PD) that not only impedes the adjuvant therapy of the malnourished patient with pancreatic cancer but also increases the length of hospitalization.

The International Study Group of Pancreatic Surgery (ISGPS) defined DGE as the inability to apply a standard diet by the end of the first postoperative week. Categories of A, B, and $\mathrm{C}$ have been established considering the inability to tolerate a solid diet by postoperative days 7,14 , and 21 or requirement or reinsertion of a nasogastric tube after the $3^{\text {rd }}, 7^{\text {th }}$, and $14^{\text {th }}$ postoperative days, respectively [1]. Various causes and possible triggers have been related to the occurrence of DGE [2-19]. These include acute changes in plasma gastrointestinal hormone (specifically motilin) levels due to duodenal resection [4-7], ischemia and congestion of the pylorus and antrum secondary to vascular compromise [9], and denervation of the stomach and duodenum due to radical resection of the surrounding tissue $[8,18]$ with subsequent pylorospasm [11]. Gastroparesis secondary to postoperative intra-abdominal complications is often, but not always associated with pancreatic fistula, peripancreatic fluid collections, or intra-abdominal abscess $[2,12,13,15,16,18]$. Additional functional abnormalities include pancreatic fibrosis [17], preoperative cholangitis [14], postoperative pancreatitis [3], alternation of the endocrinologic milieu, and perioperative blood transfusion $[18,19]$. Furthermore, the performances of classic Whipple procedure versus pylorus-preserving pancreatoduodenectomy (PPPD) [20], antecolic versus retrocolic gastric/duodenal reconstruction [21], hand-sewn versus stapled duodenojejunostomy, Billroth I versus II reconstruction, pancreaticogastrostomy versus pancreaticojejunostomy, and other operative factors that may impact the rate of DGE have been investigated [22-31]. Last but not least, technical errors such as torsion or angulation of the reconstructed alimentary tract causing DGE should be preventable $[32,33]$. We added a simple step in the procedure of 26 consecutive pancreatic head resections, which seems to alleviate DGE and has never been highlighted before.

\section{Patients and Methods}

123 pancreatic head resections either with TraversoLongmire (33) or with typical Kausch-Whipple (90) procedure were performed from 2012 to 2019 in the second 
surgical department of Evaggelismos general hospital. The selection of the procedure was based on whether the tumor invaded the duodenum or not. Mortality rate was about 16\%. 26 patients received randomly a Witzel gastrostomy with gastropexy intraoperatively, which would be closed when the postoperative ileus subsided and the discharge from the gastrostomy tube was below $500 \mathrm{ml}$ daily. Liquid diet (water, tea, and soup) would start on 5 pod and progressed depending on the patient tolerance. A gastrografin swallow was performed in addition to clinical assessment when the patients could not return to a standard diet by the end of the first postoperative week. If it would indicate slow gastric emptying, an opened pylorus, and an unobstructed antecolic gastrointestinal anastomosis, the gastrostomy tube was used as drainage. Upon tolerating solid diet, the patient would often be discharged with the gastrostomy tube closed and with instructions to appear after a week in our hospital to remove the tube.

\section{Results}

Pathologoanatomical examination of the 26 (11 female and 15 male) specimens (Figure 1) after the operation demonstrated chronic pancreatitis in 3 patients, cancer of the ampulla of Vater in 4 patients, IPMN in 1, and cancer of the head of the pancreas in 17 patients. What should be highlighted is that the examination of all specimens revealed component of chronic pancreatitis and that perineural invasion was present in all specimens with pancreatic cancer. One female (30 years) had an echinococcal cyst in the head of the pancreas. 11 (5 female and 6 male) patients had a pylorus-preserving PD while the rest 15 (9 male and 6 female) a pylorus-resecting PD (Table 1).

Only four patients (15\%), all of them with pylorusresecting $\mathrm{PD}$, exhibited signs of gastroparesis. One of them presented leakage from the pancreaticojejunal anastomosis, while another one presented postoperative hemorrhage. The rest twenty-two patients had no postoperative gastric atony, even though four of them presented anastomotic leakage. The mean $\mathrm{RBC}$ units perioperatively transfused were 3 per patient.

\section{Discussion}

Over time, it has been assumed that DGE is strongly associated with the occurrence of other postoperative complications such as fistula formation, postoperative sepsis, and reoperation. Whether the duodenum is preserved or not, DGE occurs after both classic (with antrectomy) and pylorus-preserving pancreatoduodenectomy [34-37].

Several therapeutic alternatives for the treatment of DGE are reported in the literature like the usage of prokinetic drugs (motilin, erythromycin, and cisapride), postoperative cyclic enteral feeding, and several specifications for reconstructing the alimentary tract, preservation of vagal pyloric branches, vascular structures, and length of the duodenum.

Since gastric atony after these procedures is common (20-30\%), in anticipation for prolonged requirement of gastric drainage, we regularly use a Witzel gastrostomy.

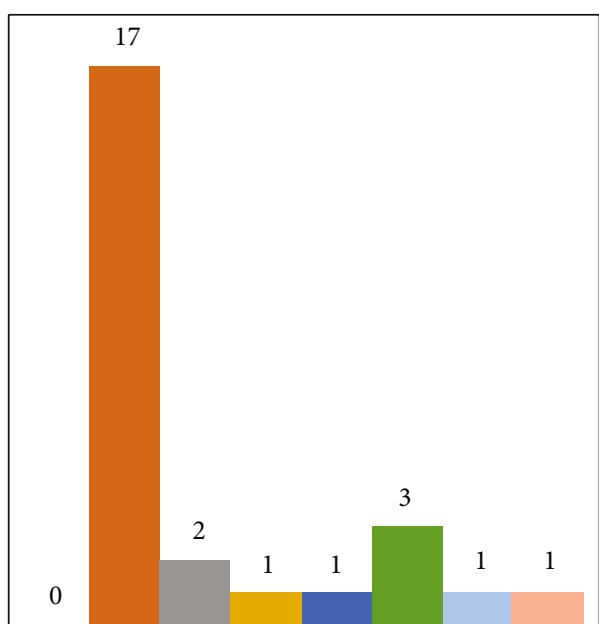

Pathology type of pancreatic cancer

Ductal adenocarcinoma

Ampullary AdenoCA

Branch type IPMN

Duodenal adenocarcinoma

Chronic pancreatitis

Echinococcal cyst

Figure 1: Pathologoanatomical studies of $26 \mathrm{PD}$.

TABLE 1: The resected intestinal length in $\mathrm{cm}$. The duodenum and jejunum are considered the main sites of motilin production. Conservation of the intestine as much as possible should result in more peristalsis and accelerated gastric emptying.

\begin{tabular}{lc}
\hline & Statistic \\
\hline Mean & 21,041 \\
95\% confidence interval for mean & \\
$\quad$ Lower bound & 19,266 \\
$\quad$ Upper bound & 22,815 \\
Median & 22,000 \\
Std. deviation & 4,4852 \\
Minimum & 15,5 \\
Maximum & 32,0 \\
Range & 16,5 \\
\hline
\end{tabular}

Indications to perform a gastrostomy, in historical order of their development, include the following: (1) to provide nutrition, (2) to allow retrograde dilatation of the esophagus, and (3) to provide postoperative decompression of the gastrointestinal tract [38]. Gilchrist (1953) was an early advocate of using a gastrostomy tube to decompress the stomach postoperatively, to avoid the complications of an indwelling nasogastric tube and to promote patient comfort [39]. Warshaw and Torchiana [40] found that patients after PPPD frequently required prolonged nasogastric intubation and could not tolerate a regular diet in the early postoperative period due to DGE.

The Witzel technique [41], as described (Figures 2-4), has proved to be safe, reliable, and simple to perform. It offers the patient comfort (since a nasogastric tube is not necessary), immediate function for decompression, and low 


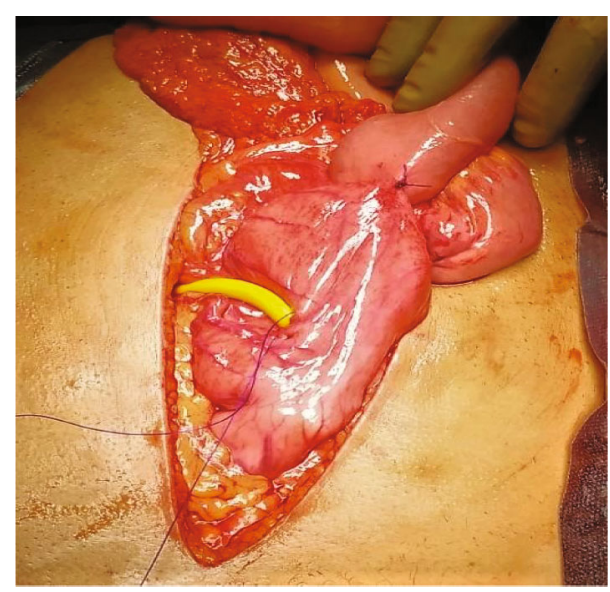

Figure 2: Two small holes, one in the center of the purse string suture (PDS 2-0) used to secure the tube after inserting it in the stomach and the other in the anterior abdominal wall, lateral to the left rectus muscle, are via electrodiathermy accomplished. A No. 18 Foley catheter is advanced through the anterior abdominal wall and into the body of the stomach, in a caudal direction. $3 \mathrm{ml}$ of saline is used to inflate the Foley balloon so that it would not slip out of the stomach (we deflate it on the first postoperative day).

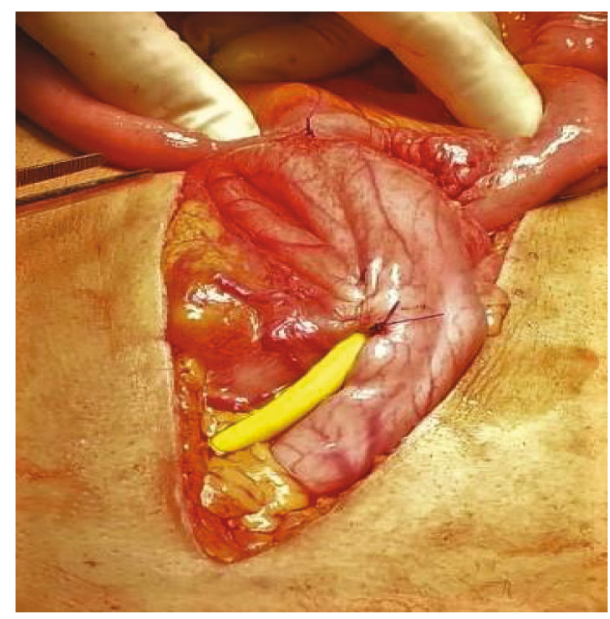

Figure 3: A serosa-lined tunnel (Witzel canal) is created with a continuous suture of the same 2-0 PDS used at the beginning.

morbidity [40, 42]. Complications include internal migration, wound infection and peritonitis, when leakage occurs, or inability to remove it and dislodgement.

The site of insertion of the gastrostomy tube is selected along the greater curvature of the body of the stomach, within approximately 2 or $3 \mathrm{~cm}$ of the gastroepiploic branches and on the anterior wall of the stomach. The selection of this site is based on two speculations.

Firstly, fixating gastrostomy on the anterior and middle portion of the stomach might not affect both gastric fundic lag phase and gastric antral motility, which are considered important for gastric emptying [31].

Secondly, fixating the stomach to the anterior wall keeps it taut enough to prevent torsion or angulation of the reconstructed GI anastomosis. Combination of gastropexy with an

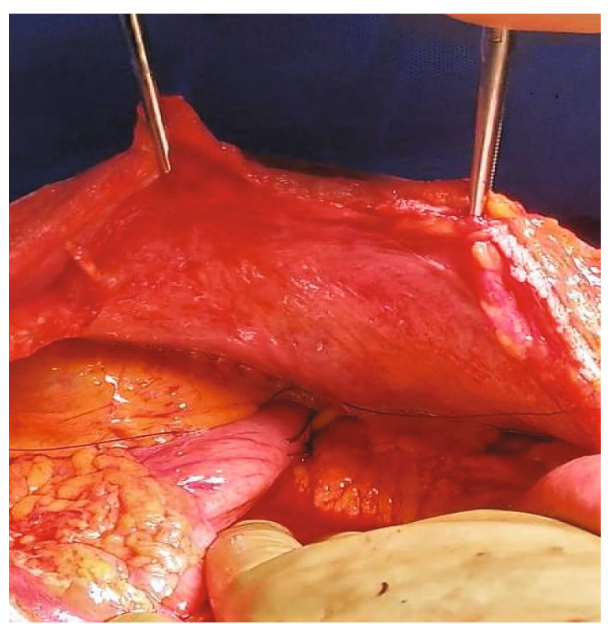

FIgURe 4: A gastropexy is performed with two single resorbable sutures, concealing the tube and anchoring the stomach to the parietal peritoneum of the left abdominal wall.

antecolic anastomosis seems to facilitate passive emptying of food into the jejunum with the help of gravity.

The gastrostomy placement provides through its "gastropexy effect" a slightly increased low esophageal sphincter (LES) pressure [43]. The speculation that it may slow gastric motility and lead to slower function of the GI anastomosis after PPPD [44] was not confirmed in our study.

\section{Conclusion}

To date, there is no reference in literature about the use of gastrostomy to prevent DGE. Our small series of patients showed that gastrostomy-gastropexy can be used, with safety and efficacy, as a preventive measure for DGE in patients undergoing pancreatoduodenectomy. Further studies and randomized trials are necessary in order to establish safe conclusions.

\section{Data Availability}

The data that support the findings of this case report are available from the corresponding author, G. Floros, upon reasonable request.

\section{Conflicts of Interest}

The authors declare that they have no conflicts of interest.

\section{References}

[1] M. N. Wente, C. Bassi, C. Dervenis et al., "Delayed gastric emptying (DGE) after pancreatic surgery: a suggested definition by the international study Group of Pancreatic Surgery (ISGPS)," Surgery, vol. 142, no. 5, pp. 761-768, 2007.

[2] B. W. Miedema, M. G. Sarr, J. A. van Heerden, D. M. Nagorney, D. C. McIlrath, and D. Ilstrup, "Complications following pancreaticoduodenectomy," Archives of Surgery, vol. 127 , no. 8, pp. 945-949, 1992. 
[3] P. W. Lin and Y. J. Lin, "Prospective randomized comparison between pylorus-preserving and standard pancreaticoduodenectomy," The British Journal of Surgery, vol. 86, no. 5, pp. 603-607, 1999.

[4] J. E. Fox, E. E. Daniel, J. Jury, and H. Robotham, "The mechanism of motilin excitation of the canine small intestine," Life Sciences, vol. 34, no. 10, pp. 1001-1006, 1984.

[5] G. Naritomi, M. Tanaka, H. Matsunaga et al., "Pancreatic head resection with and without preservation of the duodenum: different postoperative gastric motility," Surgery, vol. 120, pp. 831-837, 1986.

[6] M. Tanaka and M. G. Sarr, "Total duodenectomy: effect on canine gastrointestinal motility," The Journal of Surgical Research, vol. 42, no. 5, pp. 483-493, 1987.

[7] M. Tanaka and M. G. Sarr, "Role of the duodenum in the control of canine gastrointestinal motility," Gastroenterology, vol. 94, no. 3, pp. 622-629, 1988.

[8] A. Tanaka, T. Ueno, M. Oka, and T. Suzuki, "Effect of denervation of the pylorus and transection of the duodenum on acetaminophen absorption in rats; possible mechanism for early delayed gastric emptying after pylorus preserving pancreatoduodenectomy," The Tohoku Journal of Experimental Medicine, vol. 192, no. 4, pp. 239-247, 2000.

[9] K. M. Itani, R. E. Coleman, W. C. Meyers, and O. E. Akwari, "Pylorus-preserving pancreatoduodenectomy. A clinical and physiologic appraisal," Annals of Surgery, vol. 204, no. 6, pp. 655-664, 1986.

[10] T. Ueno, A. Tanaka, Y. Hamanaka, M. Tsurumi, and T. Suzuki, "A proposal mechanism of early delayed gastric emptying after pylorus preserving pancreatoduodenectomy," Hepato-Gastroenterology, vol. 42, no. 3, pp. 269-274, 1995.

[11] D. K. Kim, A. A. Hindenburg, S. K. Sharma et al., "Is pylorospasm a cause of delayed gastric emptying after pyloruspreserving pancreaticoduodenectomy?," Annals of Surgical Oncology, vol. 12, no. 3, pp. 222-227, 2005.

[12] O. Horstmann, H. Becker, S. Post, and R. Nustede, "Is delayed gastric emptying following pancreaticoduodenectomy related to pylorus preservation?," Langenbeck's Archives of Surgery, vol. 384, no. 4, pp. 354-359, 1999.

[13] O. Horstmann, P. M. Markus, M. B. Ghadimi, and H. Becker, "Pylorus preservation has no impact on delayed gastric emptying after pancreatic head resection," Pancreas, vol. 28, no. 1, pp. 69-74, 2004.

[14] Y. C. Park, S. W. Kim, J. Y. Jang, Y. J. Ahn, and Y. H. Park, "Factors influencing delayed gastric emptying after pylorus-preserving pancreatoduodenectomy," Journal of the American College of Surgeons, vol. 196, no. 6, pp. 859$865,2003$.

[15] H. Riediger, F. Makowiec, W. D. Schareck, U. T. Hopt, and U. Adam, "Delayed gastric emptying after pylorus-preserving pancreatoduodenectomy is strongly related to other postoperative complications," Journal of Gastrointestinal Surgery, vol. 7, no. 6, pp. 758-765, 2003.

[16] D. R. Hunt and R. McLean, "Pylorus-preserving pancreatectomy: functional results," The British Journal of Surgery, vol. 76, pp. 1-176, 1989.

[17] H. Murakami, H. Suzuki, and T. Nakamura, "Pancreatic fibrosis correlates with delayed gastric emptying after pyloruspreserving pancreaticoduodenectomy with pancreaticogastrostomy," Annals of Surgery, vol. 235, no. 2, pp. 240-245, 2002.
[18] A. Ross, S. Mohammed, G. VanBuren et al., "An assessment of the necessity of transfusion during pancreatoduodenectomy," Surgery, vol. 154, no. 3, pp. 504-511, 2013.

[19] H. C. Kim, T. Suzuki, T. Kajiwara, T. Miyashita, M. Imamura, and T. Tobe, "Exocrine and endocrine stomach after gastrobulbar preserving pancreatoduodenectomy," Annals of Surgery, vol. 206, no. 6, pp. 717-727, 1987.

[20] F. J. Huettner, C. Fitzmaurice, G. Schwarzer et al., "Pyloruspreserving pancreaticoduodenectomy ( $p p$ Whipple) versus pancreaticoduodenectomy (classic Whipple) for surgical treatment of periampullary and pancreatic carcinoma," Cochrane Database of Systematic Reviews, vol. 2, article CD006053, 2016.

[21] G. R. Joliat, I. Labgaa, N. Demartines, M. Schäfer, and P. Allemann, "Effect of antecolic versus retrocolic gastroenteric reconstruction after pancreaticoduodenectomy on delayed gastric emptying: a meta-analysis of six randomized controlled trials," Digestive Surgery, vol. 33, no. 1, pp. 15-25, 2016.

[22] Y. Sakamoto, Y. Yamamoto, S. Hata et al., "Analysis of risk factors for delayed gastric emptying (DGE) after 387 pancreaticoduodenectomies with usage of 70 stapled reconstructions," Journal of Gastrointestinal Surgery, vol. 15, no. 10, pp. 17891797, 2011.

[23] T. H. Goei, M. I. van Berge Henegouwen, M. J. Slooff, T. M. van Gulik, D. J. Gouma, and E. H. Eddes, "Pylorus-preserving pancreatoduodenectomy: influence of a Billroth I versus a Billroth II type of reconstruction on gastric emptying," Digestive Surgery, vol. 18, no. 5, pp. 376-380, 2001.

[24] C. Bassi, M. Falconi, E. Molinari et al., "Reconstruction by pancreaticojejunostomy versus pancreaticogastrostomy following pancreatectomy: results of a comparative study," Annals of Surgery, vol. 242, no. 6, pp. 767-773, 2005.

[25] L. Fernández-Cruz, R. Cosa, L. Blanco, M. A. López-Boado, and E. Astudillo, "Pancreatogastrostomy with gastric partition after pylorus-preserving pancreatoduodenectomy versus conventional pancreatojejunostomy," Annals of Surgery, vol. 248, no. 6, pp. 930-938, 2008.

[26] T. Keck, U. F. Wellner, M. Bahra et al., "Pancreatogastrostomy versus pancreatojejunostomy for RECOnstruction after PANCreatoduodenectomy (RECOPANC, DRKS 00000767)," Annals of Surgery, vol. 263, no. 3, pp. 440-449, 2016.

[27] P. Pessaux, A. Sauvanet, C. Mariette et al., "External pancreatic duct stent decreases pancreatic fistula rate after pancreaticoduodenectomy," Annals of Surgery, vol. 253, no. 5, pp. 879885, 2011.

[28] D. M. Walters, A. L. Shada, D. J. LaPar, R. B. Adams, and T. W. Bauer, "A long gastrojejunostomy is associated with decreased incidence and severity of delayed gastric emptying after pancreaticoduodenectomy," Pancreas, vol. 44, no. 8, pp. 12731279, 2015.

[29] Y. Watanabe, T. Ohtsuka, H. Kimura et al., "Braun enteroenterostomy reduces delayed gastric emptying after pyloruspreserving pancreatoduodenectomy: a retrospective review," American Journal of Surgery, vol. 209, no. 2, pp. 369-377, 2015.

[30] R. Ravikumar, C. Sabin, M. Abu Hilal et al., "Portal vein resection in borderline resectable pancreatic cancer: a United Kingdom multicenter study," Journal of the American College of Surgeons, vol. 218, no. 3, pp. 401-411, 2014.

[31] J. W. Kunstman, A. L. Fonseca, M. M. Ciarleglio, X. Cong, A. Hochberg, and R. R. Salem, "Comprehensive analysis of variables affecting delayed gastric emptying following pancreaticoduodenectomy," Journal of Gastrointestinal Surgery, vol. 16, no. 7, pp. 1354-1361, 2012. 
[32] R. K. Jex, J. A. van Heerden, B. G. Wolff, R. L. Ready, and D. M. Ilstrup, "Gastrointestinal anastomoses. Factors affecting early complications," Annals of Surgery, vol. 206, no. 2, pp. 138$141,1987$.

[33] M. Sugiyama, N. Abe, H. Ueki, T. Masaki, T. Mori, and Y. Atomi, "A new reconstruction method for preventing delayed gastric emptying after pylorus-preserving pancreatoduodenectomy," The American Journal of Surgery, vol. 187, no. 6, pp. 743-746, 2004.

[34] J. D. Eisenberg, E. L. Rosato, H. Lavu, C. J. Yeo, and J. M. Winter, "Delayed gastric emptying after pancreaticoduodenectomy: an analysis of risk factors and cost," Journal of Gastrointestinal Surgery, vol. 19, no. 9, pp. 1572-1580, 2015.

[35] U. Klaiber, P. Probst, O. Strobel et al., "Meta-analysis of delayed gastric emptying after pylorus-preserving versus pylorus-resecting pancreatoduodenectomy," The British Journal of Surgery, vol. 105, no. 4, pp. 339-349, 2018.

[36] G. Sato, Y. Ishizaki, J. Yoshimoto, H. Sugo, H. Imamura, and S. Kawasaki, "Factors influencing clinically significant delayed gastric emptying after subtotal stomach-preserving pancreatoduodenectomy," World Journal of Surgery, vol. 38, no. 4, pp. 968-975, 2014.

[37] J. M. Garonzik-Wang and M. B. Majella Doyle, "Pylorus preserving pancreaticoduodenectomy," Clinical Liver Disease, vol. 5, no. 3, pp. 54-58, 2015.

[38] M. W. Gauderer and T. A. Stellato, "Gastrostomies: evolution, techniques, indications, and complications," Current Problems in Surgery, vol. 23, no. 9, pp. 661-719, 1986.

[39] R. K. Gilchrist, "Postoperative decompression of the stomach and jejunum by gastrostomy," JAMA, vol. 152, no. 3, p. 232, 1953.

[40] A. L. Warshaw and D. L. Torchiana, "Delayed gastric emptying after pylorus-preserving pancreaticoduodenectomy," Surgery, Gynecology \& Obstetrics, vol. 160, pp. 1-4, 1985.

[41] O. Witzel, “Zur technik der magenfistelalegung," Zentralblatt für Chirurgie, vol. 32, pp. 601-604, 1891.

[42] H. Ono, T. Azuma, H. Miyaji et al., "Effects of percutaneous endoscopic gastrostomy tube placement on gastric antral motility and gastric emptying," Journal of Gastroenterology, vol. 38, no. 10, pp. 930-936, 2003.

[43] D. A. Johnson, J. F. Hacker III, S. B. Benjamin, C. A. Ciarleglio, and S. J. Chobanian, "Percutaneous endoscopic gastrostomy effects on gastroesophageal reflux and the lower esophageal sphincter," The American Journal of Gastroenterology, vol. 82, no. 7, pp. 622-624, 1987.

[44] P. C. Shellito and R. A. Malt, "Techniques and complications," Annals of Surgery, vol. 201, no. 2, pp. 180-185, 1985.

[45] A. D. Parmar, K. M. Sheffield, G. M. Vargas et al., "Factors associated with delayed gastric emptying after pancreaticoduodenectomy," $H P B$, vol. 15, no. 10, pp. 763-772, 2013.

[46] D. Lytras, K. Paraskevas, C. Avgerinos et al., "Therapeutic strategies for the management of delayed gastric emptying after pancreatic resection," Archives of Surgery, vol. 392, pp. 1-12, 2006.

[47] H. Wakamatsu, S. Nagamachi, R. Nishii et al., "Effect of percutaneous endoscopic gastrostomy on gastrointestinal motility: evaluation by gastric-emptying scintigraphy," Nuclear Medicine Communications, vol. 29, no. 6, pp. 562-567, 2008. 